\title{
Biopolymer Test Kit for Colorimetric Detection of Chlorine in Water
}

\author{
Worawit Wongniramaikul $1^{1,2, a,{ }^{*}}$, Hataikran Sangtong ${ }^{1, b}$, and Aree Choodum ${ }^{1, c}$ \\ 1 Faculty of Technology and Environment, Prince of Songkla University, Phuket Campus, Kathu, Phuket \\ 83120, Thailand \\ 2 Research Program: The Development of Management System for Reduction and Control of Water \\ Contamination and Distribution in Songkhla Lake Basin and the Western Coastline of the South of \\ Thailand, Center of Excellence on Hazardous Substance Management (HSM), Bangkok 10330, Thailand \\ E-mail: a,*worawit.won@phuket.psu.ac.th (Corresponding author), bphone.hs@hotmail.com, \\ caree.c@phuket.psu.ac.th
}

\begin{abstract}
The objective of the study was to fabricate the colorimetric sensor of biodegradable material for free chlorine determination. The colorimetric reagent of N,N-diethyl-pphenylenediamine sulfate (DPD) was entrapped in the hybrid biopolymer film of agar (AG) and tapioca starch (TAS) and it was coated on the plastic micro-PCR tube. The pink product obtained from the reaction between DPD reagent and chlorine could indicate the presence of residual chlorine in the water. The condition for the sensor film synthesis was optimized by the digital image analytical technique with mobile phone application. The results were showed that Red-Green-Blue (RGB) intensity of reaction product was not changed, even through the DPD reagent was added over $0.2 \mathrm{~g} / \mathrm{mL}$. The addition of $16 \mathrm{~g} / \mathrm{L}$ EDTA in the buffer solution could reduce the interference effect from some metals, especially $\mathrm{Fe}^{3+}$, contaminated in water sample. The water $\mathrm{pH}$ could be maintained for best analysis at the volume ratio between buffer and DPD solution of 0.5:1. The incubation of colorimetric film at $60{ }^{\circ} \mathrm{C}$ and 60 minutes provided the best sensor performance with fast analysis of $1 \mathrm{~min}$ reaction time. In conjunction with the digital image colorimetry (DIC), the developed test kit did not provided only the qualitative information, but the rapid quantitative analysis could be also fulfilled. A wide linear range of 0.3 to $15 \mathrm{mg} / \mathrm{L}$ chlorine concentration with good linearity $\left(\mathrm{R}^{2}>0.99\right)$ was achieved by this coupled technique. The application of biopolymer film to various kind of real water samples showed the good performances, which were comparable with the standard spectrophotometry (no significantly different results at 95\% confidence level). These could promote the use of biopolymer test kit as the environmentally-friendly analytical method for chlorine in water.
\end{abstract}

Keywords: Biopolymer, colorimetric sensor, free chlorine, RGB intensity, digital image analysis.

ENGINEERING JOURNAL Volume 25 Issue 4

Received 4 December 2020

Accepted 29 December 2020

Published 30 April 2021

Online at https://engj.org/

DOI:10.4186/ej.2021.25.4.57 


\section{Introduction}

Chlorine $\left(\mathrm{Cl}_{2}\right)$ is a typical oxidizing agent widely used for water disinfection in tap water, drinking water, swimming pools and recycled water from wastewater $[1,2]$. When a concentration of liquid solid or gas chlorine are added into water, they are transformed into hypochlorous acid $(\mathrm{HClO})$ and hypochlorite ion $\left(\mathrm{ClO}^{-}\right)$ which generally defined as free residual chlorine [3]. Too low chlorine concentration in water cannot kill pathogenic bacteria and causes many hazards of an insufficient disinfection [4]. On the other hand, free residual chlorine with too high level might produce many undesirable byproducts such as trihalomethanes (THMs) $[5,6]$, which have been proved to be carcinogenic and harmful to human and animals [7]. The World Health Organization (WHO) has recommended that acceptable chlorine level in drinking water should not exceed 5 mg/L [8]. The United States Environmental Protection Agency (EPA) has established the maximum free chlorine concentration level of $4 \mathrm{mg} / \mathrm{L}$ for both swimming pools, when it is opened to the public, and drinking water $[9,10]$. In Thailand, the concentration of free chlorine residual in natural waters allowed by legislation should not exceed $1 \mathrm{mg} / \mathrm{L}$ [11].

A large number of analytical methods have been developed for determination of free chlorine in water including ion chromatography [12], chemiluminescence [13], fluorescence [14], amperometry [15], and spectrophotometry [16]. Of all methods, the most commonly used one is a colorimetric method, which is based on the reaction of $\mathrm{N}, \mathrm{N}$-diethyl-p-phenylenediamine (DPD) reagent $[17,18]$ and analysis of free chlorine by spectrophotometer. However, the application of conventionally spectrophotometric technique is suffered from some drawbacks, such as nonportability of laboratory instrument and low capability for real-time or on-line monitoring. In recent years, the digital image-based methods have frequently been used as an alternative to develop fast and low-cost colorimetric detections for quantitative chemical analysis [19-21]. The principle of these methods is based on the analysis of RGB (red-green-blue) color system from the digital images of colorimetric product. Various color analysis program, e.g. Adobe Photoshop and MATLBbased program, could be used to provide the recorded RGB values [22, 23]. Also, the digital image colorimetry was successfully developed for the detection by using other commercial applicationor customed-built programs on the smartphone [24, 25].

The colorimetric sensor showed the advantage of rapid and on-site measurement. It is based on the entrapment of color reagent in support materials, e.g. solgel, hydrogel and synthetic polymer. Even through, most substrates trend to be recalcitrant to naturally biodegraded process and some can be dissolved in water or widespread to the environment. For this reason, the natural polymers, especcially a group of polysaccharides such as starch, become considerably interested for the development of biodegradable sensors [26-29]. Several studies were performed to analyze the properties of starch-based films [30-32] and they reported that films possessed the poor mechanical properties and high moisture sensitivity. However, the addition of agar was able to enhance the tensile strength of starch-based film to obviously reduction on elongation [33, 34], and also showed the good compatibility with the starch texture $[35,36]$. Thus, agar-strach blending film is an interesting alternative as a biopolymer for the development of chemical sensor due to a low cost polymer and ecofriendly material.

The objectives of this study was focused on the development of the chemical sensor from hybrid biopolymer of starch and agar, which could be applied with digital image technique for the determination of free residual chlorine in water. The testkit of film sensor was fabricated in the small plastic tube to promote the portability for the field measurement, less reagent consumption and environmentally friendly method.

\section{Experiment}

\subsection{Chemicals and Materials}

Sodium hypochlorite $\mathrm{NaOCl}$ with available chlorine $7 \% \mathrm{w} / \mathrm{w}$ ) was purchased from Carlo Erba (Milan). N,Ndiethyl-p-phenylenediamine sulfate (DPD) was obtained from Sigma-Aldrich (USA)., and the other reagents were obtained from Ajax Finechem (Australia).

$\mathrm{NaOCl}$ solution was used as the free chlorine with concentration of approximately $5 \mathrm{mg}$ as $\mathrm{Cl}_{2} / \mathrm{L}$ for all tests, if not mentioned others and it was freshly prepared for daily use. The plastic micro-PCR tube $1.5 \mathrm{~mL}$ was used as a reaction container, where a coated film was on its lid (as showed in Fig. 1.)

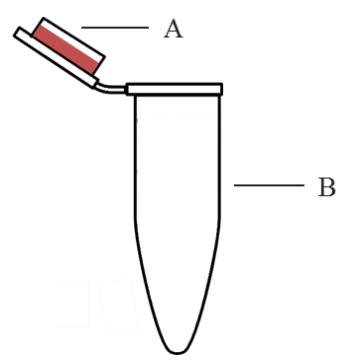

Fig. 1. Testkit with a thin sensor film coated on the lid (A) of the plastic micro-PCR tube (B).

\subsection{Preparation of Sensing Polymers}

\subsubsection{Colorimetric reagents}

There were 2 reagents related to the colorimetric reaction of free chlorine, i.e. N,N-diethyl-p-phenylenediamine (DPD) sulfate reagent and phosphate buffer. The DPD 
reagent as chromogenic species was daily prepared by dissolving appropriate amount of DPD sulphate in 10 $\mathrm{mL}$ ultrapure water containing $80 \mu \mathrm{L}$ of $3 \mathrm{M} \mathrm{H}_{2} \mathrm{SO}_{4}$ solution ( $\mathrm{pH} 2$ ) before stored in an amber bottle to avoid any interferences from a light. Phosphate buffer at $\mathrm{pH} 6$ was prepared by dissolving $0.24 \mathrm{~g} \mathrm{Na}_{2} \mathrm{HPO}_{4}$ and $0.46 \mathrm{~g}$ $\mathrm{KH}_{2} \mathrm{PO}_{4}$ in $10 \mathrm{~mL}$ of ultrapure water with proper disodium ethylenediaminetetraacetic acid (EDTA) and it was stored in a refrigerator at $4^{\circ} \mathrm{C}$ before used.

\subsubsection{Agar-starch hybrid polymer films}

Tapioca starch (TAS) (Erawan Brand, Nakhon Pathom, Thailand) and agar (AG) (Nang Kwak Brand, Bangkok Thailand), which were used as the film forming components, could be easily purchased from a local market in Phuket, Thailand. A mass series of agar $(0.025$, $0.05,0.1,0.2 \mathrm{~g})$ and starch $(0.05,0.1,0.2,0.3,0.4 \mathrm{~g})$ solution were prepared in $10 \mathrm{~mL}$ ultrapure water purified by a water purification system (Merck, Darmstadt, Germany). Each solution was simultaneously heated at $90{ }^{\circ} \mathrm{C}$ for $15 \mathrm{~min}$ before cooled down to ambient temperature for $5 \mathrm{~min}$. Then, both solutions were mixed well at a 2:1 volume ratio of AG: TAS solution under a magnetic stirring condition and the clear solution (AGTAS) was obtained in a few seconds.

The sensing film was fabricated by blending the appropriate proportion of colorimetric reagent and buffer mixture into $3.5 \mathrm{~mL}$ AG-TAS solution. $100 \mu \mathrm{L}$ of the resulting mixture was then dropped on the inside lid of a micro-PCR tube and dried in hot air oven at $60{ }^{\circ} \mathrm{C}$ for 60 minutes. After cooled to room temperature, the sensor testkit was in a ready-to-use condition with $1 \mathrm{~mL}$ water sample of free chlorine.

\subsection{RGB Imaging System and Colorimetric Quantification of Chlorine}

Since the principle of digital image analysis was based on the measurement of light reflection from the reaction product, the custom-built analytical box was set up to limit the detection interference from the environmental light, such as sunlight. A photographic box with $15.5 \mathrm{~cm}$ width $\times 15.5 \mathrm{~cm}$ length $\mathrm{x} 19.5 \mathrm{~cm}$ height (Fig. 2) was made of opaque black corrugated plastic board with a white interior. Three light-emitting diode (LED) rows were placed on the walls inside the box as light sources. Front side of the box was perforated for an installation of camera built in the mobile phone (iPhone 7 with 12MP and backside illuminated CMOS), which was operated in the flash-off mode (f/1.8 aperture and ISO 50) throughout experiments.

A series of chlorine standard solution $(0.1-50 \mathrm{mg} / \mathrm{L})$ was freshly prepared to prevent any errors from unstability of chlorine. Colorimetric analysis was performed when $1 \mathrm{~mL}$ of water sample was poured into a testkit tube with the biodegradable hybrid film on the lid and mixed by shaking for $1 \mathrm{~min}$. The resultant pink products were appeared in the tube, due to the reaction between free chlorine and DPD dissolved from the film. In a process of digital image colorimetry (DIC), three sensor tubes was hung on the top of the box and they was photographed for 6 images $(4032 \times 3024$ pixels, 1.33 $\mathrm{MB})$. The average intensities of the red, green and blue colors (RGB values) across six images from three sensors were investigated using an in-house RGB analysis program. Those average RGB data of each standard concentration were used as a single data point to establish calibration curve by Microsoft Excel 2010 for further chlorine quantification.

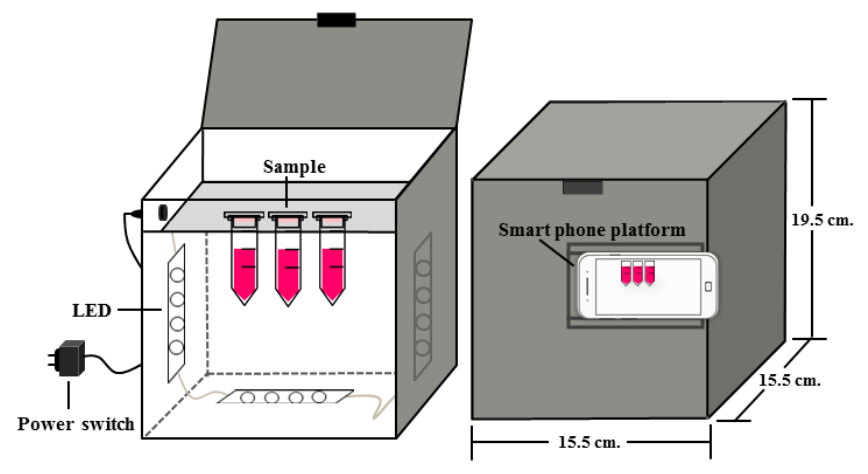

Fig. 2. A custom built photographic box.

\subsection{Analysis of Real Sample}

Real samples were analyzed by using the biopolymer test kit and DIC for measurement of chlorine concentration. These grab samples were randomly collected from different kinds of water possibly contaminated by chlorine, i.e. the swimming pool, salt water pool, tap water and sea water at Patong beach, Phuket. Each sampling point was done with three replicates of samples. The concentration of chlorine in all water samples were analyzed by the developed test kit coupled with DIC within an hour after collection. Those average concentration were compared with the results from standard spectrophotometric method, or named as DPD colorimetric method [37].

\section{Results and Discussion}

\subsection{Effect of Film Content on Reaction Product} 3.1.1. Concentration of DPD and sulfuric acid in
chromogenic reagent

A colorimetric test of chlorine was based on the reaction between free chlorine and DPD chromogenic species, i.e. a pink product of Würster dye was formed when DPD reacts with small amounts of chlorine [16]. Thus, the determination of DPD concentration in the hybrid film plays an important role to chlorine analysis. Moreover, the chemical cost was one of reasons prohibited someone to use any methods to detect the 
concerned pollutant. Because of these, the effect of DPD concentration on the color intensity of reaction product was studied in the range of $0.0011-0.6 \mathrm{~g} / \mathrm{mL}$.
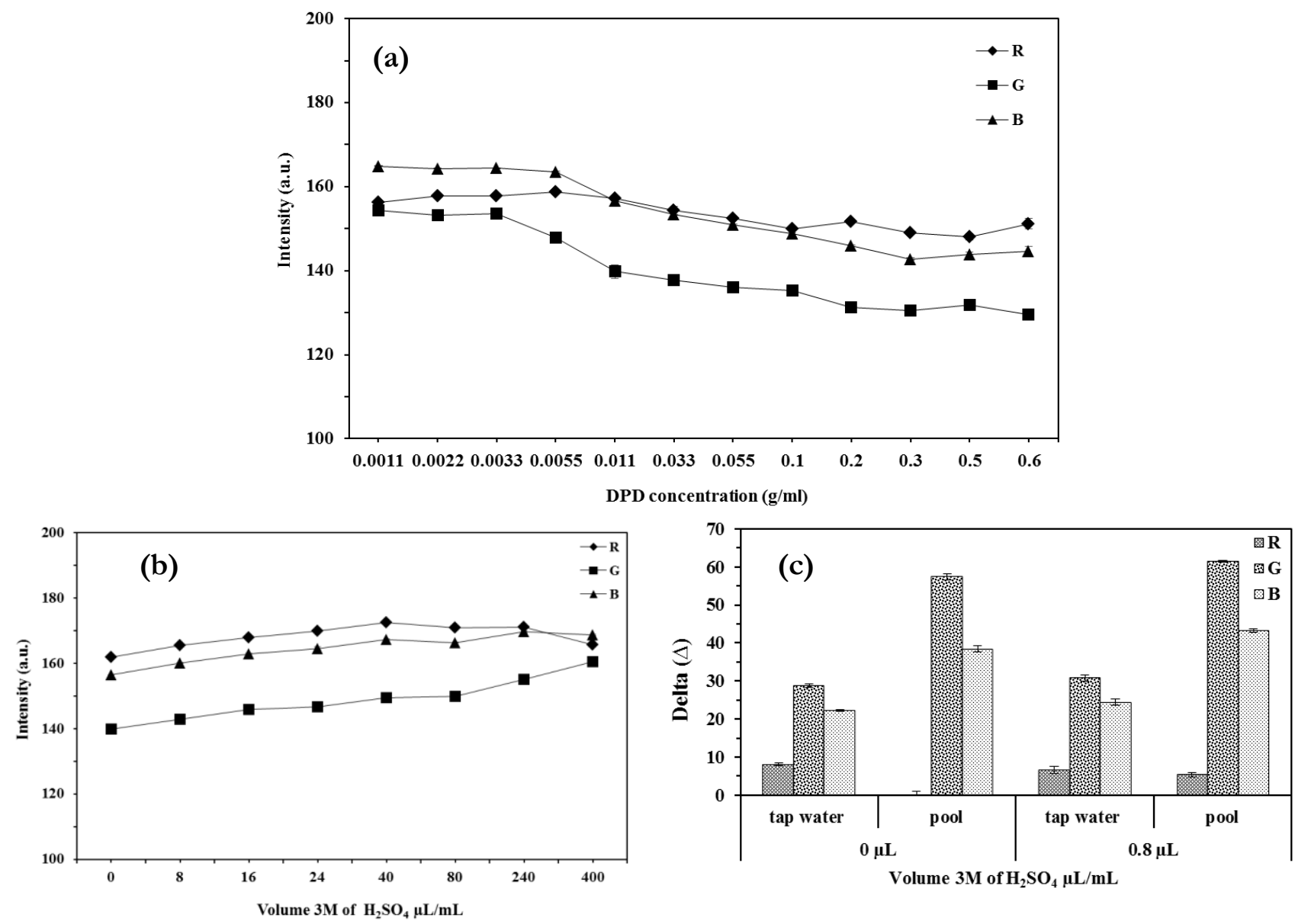

Fig. 3. (a) Effect of DPD concentration in film on RGB intensities, (b) Effect of sulfuric acid concentration in film on RGB intensities and (c) the application of film sensor with/without the sulfuric acid to real water samples.

As showed in Fig. 3(a), the red intensity was higher than the blue and green, respectively. This was because the reaction product was pink. The refection of red color was highest among others. In constrast, the green intensity was lowest. This was attributed to its complimentary color of red. The results in Fig. 3(a) were also revealed that the color intensity was decreased with the increasing DPD concentration in the range of below $0.2 \mathrm{~g} / \mathrm{mL}$. This caused by more reaction product formation leading to the strengthen color and lower light reflection. Even through, the intensity became constant after $0.2 \mathrm{~g} / \mathrm{mL}$ DPD concentration. It might be due to the chlorine was used up. Therefore, a concentration of $0.2 \mathrm{~g} / \mathrm{mL}$ of the DPD reagent contant was applied to form the colorimetric film.

The DPD was unstable to the oxidation from either atmospheric oxygen or dissolved oxygen presented in the prepared water. It was reported that the oxidation of DPD by oxygen was $\mathrm{pH}$ dependent [38]. Therefore, the solution of $3 \mathrm{M}$ sulfuric acid was recommended to add into the DPD reagent so as to lower the $\mathrm{pH}$ and retard the oxidation of DPD species. The effect of concentrated sulfuric acid volume in DPD reagent was therefore investigated from 0 to $400 \mu \mathrm{L} / \mathrm{mL}$. However, the results in Fig. 3(b) suggested that the sensor response was decreased with the increasing volume of acid solution. In fact, many kinds of waters might often contain the dissolved oxygen, thus the sensors with/without acid were tested with the real water sample to monitor the effect of DPD loss from oxidation. The experiment was designed by the application of the $0.8 \mu \mathrm{L}$ of $3 \mathrm{M}$ sulfuric acid into $1 \mathrm{~mL}$ DPD reagent used for the film fabrication. The sensor film was tested with samples of the tap water and swimming pool and compared the results from the sensor of no acid addition. Since the digital image colorimetry was based on the measurement of object color, the color of background sample could interfere to RGB light intensity. In order to eliminate the interference from background color of water sample, the RGB intensity of blank was substracted from those of sample. According to Fig. 3(c), it was clear that RGB intensity difference between the reaction product and 
blank obtained from the sensor film with $0.8 \mu \mathrm{L} / \mathrm{mL}$ sulfuric acid was better than the sensor without acid for both kinds of real samples. Thus, the addition of $0.8 \mu \mathrm{L}$ of $3 \mathrm{M}$ sulfuric acid was recommended as the good proportion of $1 \mathrm{~mL}$ DPD reagent used for the film fabrication.

3.1.2. Concentration of EDTA in a phosphate buffer solution

EDTA was well-known as a powerful chelating agent, which could form the higly stable complex with a metal ligand. It was suggested to insert into the buffer solution so as to eliminate the metal interference in water sample. In this study, $\mathrm{Fe}^{3+}$ was selected as nominal metal, because it was often found in many kinds of water, e.g. surface water, groundwater and even tap water for some cases. According to Fig. 4(a), various $\mathrm{Fe}^{3+}$ concentration was added into 5 $\mathrm{mg} / \mathrm{L}$ chlorine solution and it was found that the presence of $\mathrm{Fe}^{3+}$ would be not affected to the measurement of free chlorine, if its concentration was less than $50 \mathrm{mg} / \mathrm{L}$. This indicated that $\mathrm{Fe}^{3+}$ could competitively react with DPD to form the pink dye reaction product. Therefore, it was necessary to add EDTA into the buffer solution to reduce the interference effect of $\mathrm{Fe}^{3+}$. The appropriate EDTA concentration in the range $0-28 \mathrm{~g} / \mathrm{L}$ was investigated for the chlorine sample containing $50 \mathrm{mg} / \mathrm{L}$ $\mathrm{Fe}^{3+}$ ion and the results were displayed in Fig. 4(b). It was noticed that the increasing EDTA concentration increased in the RGB intensity ratio between the chlorine sample with $\mathrm{Fe}^{3+}$ and those without $\mathrm{Fe}^{3+}$. The ratio was risen up closely to 1.0, when the amount of EDTA was more than $16 \mathrm{~g} / \mathrm{L}$. This implied that the optimum concentration of EDTA in buffer solution, which could mitigate the problem of metal interference, was $16 \mathrm{~g} / \mathrm{L}$.
0

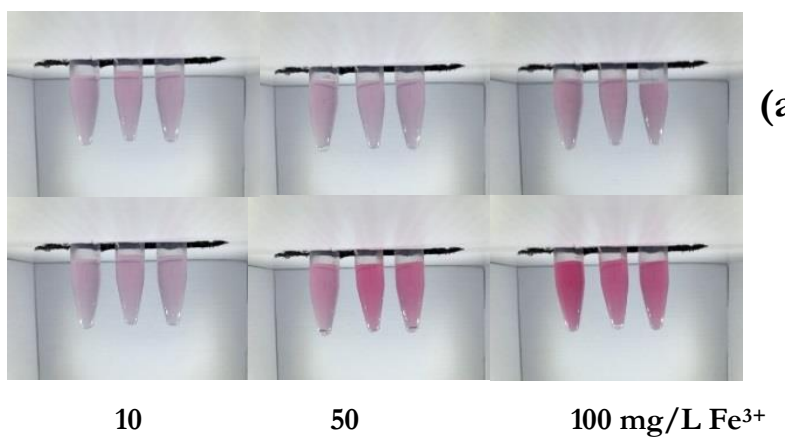

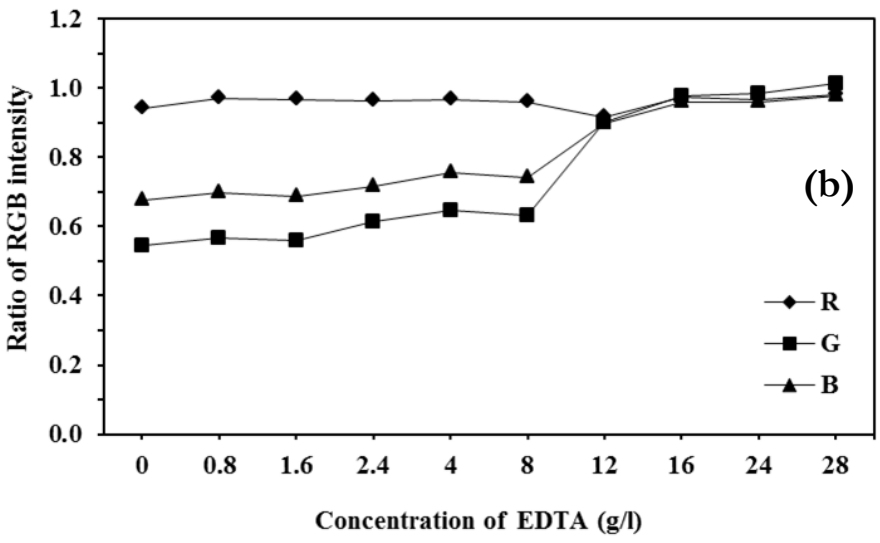

Fig. 4. (a) the interference effect from the presence of $\mathrm{Fe}^{3+}$ on the measurement of $5 \mathrm{mg} / \mathrm{L}$ chlorine and (b) the effect of EDTA concentration on the RGB intensities ratio between the chlorine sample with $\mathrm{Fe}^{3+}$ and without $\mathrm{Fe}^{3+}$.

\subsubsection{Volume ratio of the phosphate buffer to DPD reagent}

The phophate buffer played an important role to maintain the solution $\mathrm{pH}$ and stabilize the reaction product, leading to enhance the detection sensitivity [16, 18]. In this study, the sensor film was fabricated from three portion of solution, i.e. DPD reagent, phosphate buffer and hybrid biopolymer (AG and TAS). To monitor the effect of buffer solution on the colorimetric reaction, the proportional ratio of phosphate buffer to DPD reagent volume was varied at $0.5: 1,1: 1,2: 1$ and $3: 1$ $\mathrm{mL}$. The volume of biopolymer was adjusted corespondingly with those ratio to keep the total volume of mixed solution to be $5 \mathrm{~mL}$, as showed in Table 1 .

In general, the free chlorine was employed in the disinfecting process for the swimming pool and tap water The standard $\mathrm{pH}$ of swimming pool and tap water was recommended ar 7.2- -7.6 and 6.5-8.5, respectively. Thus, the effect of buffer and DPD ratio was studied in the range of $0: 1$ to 3:1. As presented in Fig. 5, there was insignificant difference in RGB intensity of the ratio between 0.5-2. To save the chemical cost and reduce the chemical waste after analysis, the ratio of phosphate buffer and DPD reagent was suggested at 0.5: 1 for testkit production.

Table 1. Combination ratio of phosphate buffer to DPD reagent in the biopolymer blends for $5 \mathrm{~mL}$ of total solution.

\begin{tabular}{cccc}
\hline $\begin{array}{c}\text { Ratio of } \\
\text { reagents }\end{array}$ & $\begin{array}{c}\text { Phosphate } \\
\text { buffer }(\mathbf{m L})\end{array}$ & $\begin{array}{c}\text { DPD } \\
\text { reagent } \\
(\mathbf{m L})\end{array}$ & $\begin{array}{c}\text { AG+CAS } \\
(\mathbf{m L}) \\
(2: 1 \text { ratio) }\end{array}$ \\
\hline $0: 1$ & 0 & 1.0 & 4 \\
$0.5: 1$ & 0.5 & 1.0 & 3.50 \\
$1: 1$ & 1.0 & 1.0 & 3.0 \\
$2: 1$ & 2.0 & 1.0 & 2.0 \\
$3: 1$ & 3.0 & 1.0 & 1.0 \\
\hline
\end{tabular}



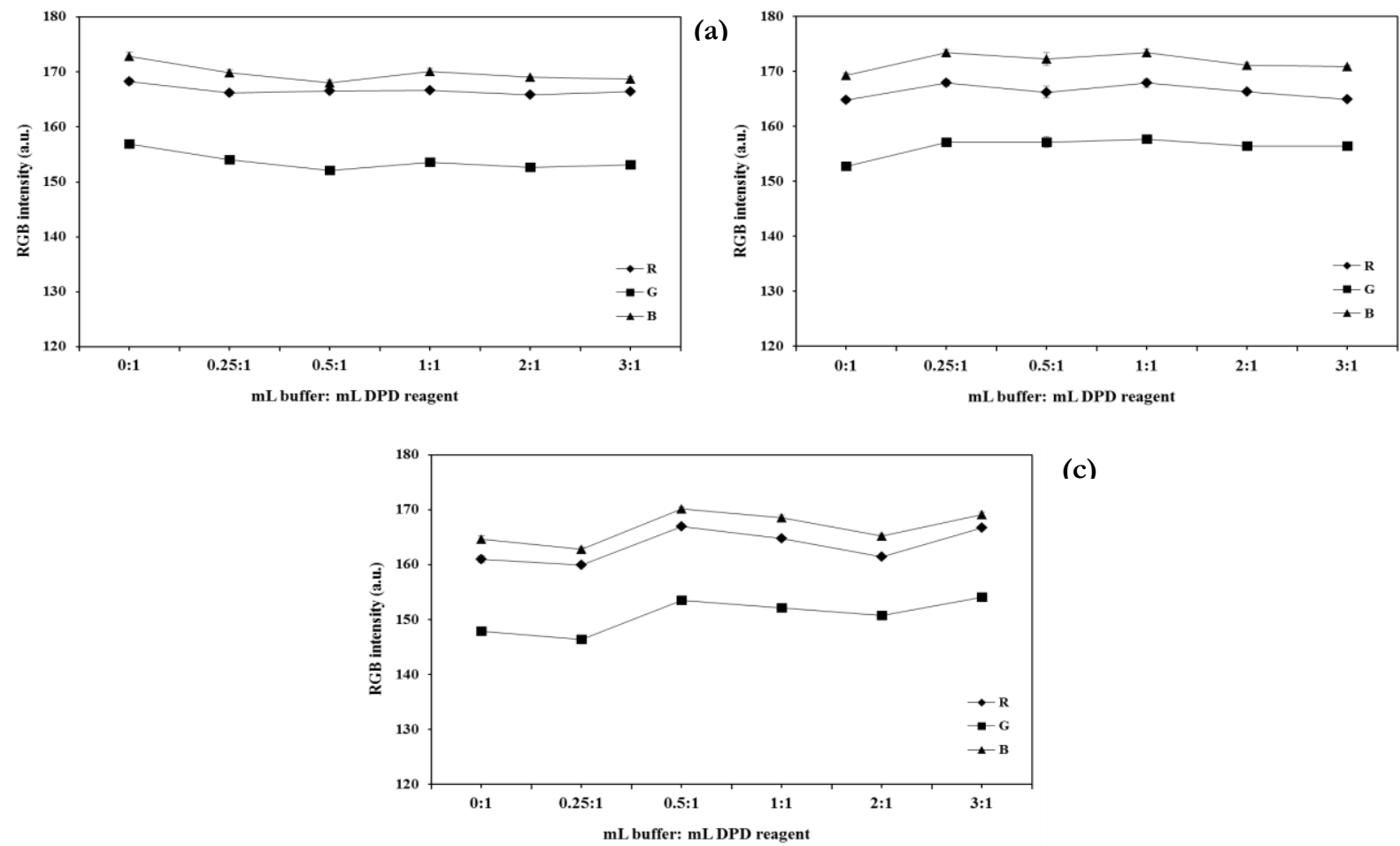

(c)

Fig. 5. Effect of the volume ratio between phosphate buffer and DPD reagent on RGB intensities at (a) sample pH 6, (b) $\mathrm{pH} 7$ and (c) $\mathrm{pH} 8$.

\subsubsection{Effect of hybrid biopolymer component}

It has been reported that $A G$ was able to provide a very good cohesive matrix, which contributed to enhance the mechanical properties of polysaccharide based film. Besides, the blending AG with TAS increased the surface wettability, inducing an improvement in elongation and tensile strength [36]. In this research, the biopolymer was generated from the blending of $A G$ and TAS solution at the ratio of $2: 1(\mathrm{v} / \mathrm{v})$, before mixing with $\mathrm{DPD}$ and buffer solution at above proportion. The optimum concentration used to prepare the AG solution was studied in the range of 2.5-20 g/L, while those for TAS solution was $5-40 \mathrm{~g} / \mathrm{L}$. Their results was presented in Fig. 6(a) and (b), respectively.

According to Fig. 6(a), the increasing in agar concentration decreased the RGB intensity, or built up the magnitude of reaction product. It was attributed that

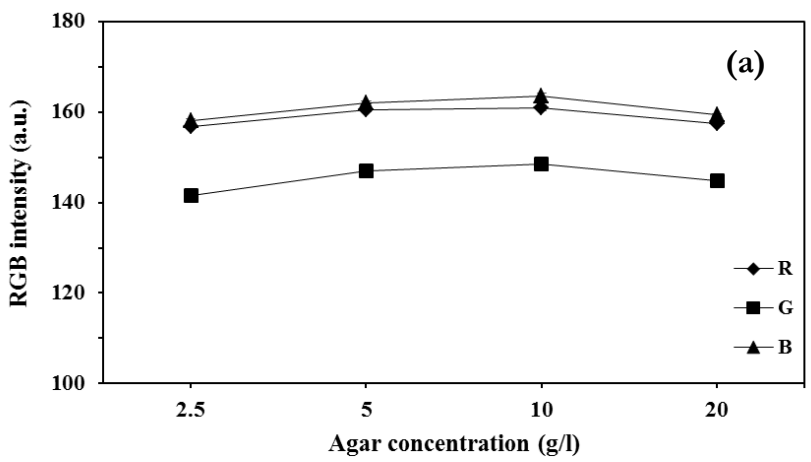

the structure of biopolymer with more agar concentration would foster the characteristics of wettability [36], which could possibly promote the diffusion of colorimetric reagent from sensor film, leading to accelerate the reaction kinetic. However, the excess of agar concentration caused to reduce the flexibility of sensor film and affected to the difficulty of fabricated process. The reults in Fig. 6(b) showed the same phenomenon as the agar section. The existence of high starch concentration reduced the formation of color reaction product. It was because the increasing in the starch molecule would patronize the denser structure of biopolymer. This could impede the diffusion of chromogenic species from the polymer film to water layer, leading to lower reaction rate. That's why the concentration of $2.5 \mathrm{~g} / \mathrm{L}$ of $\mathrm{AG}$ and $5 \mathrm{~g} / \mathrm{L}$ of TAS was chosen as good optimum condition for film forming.

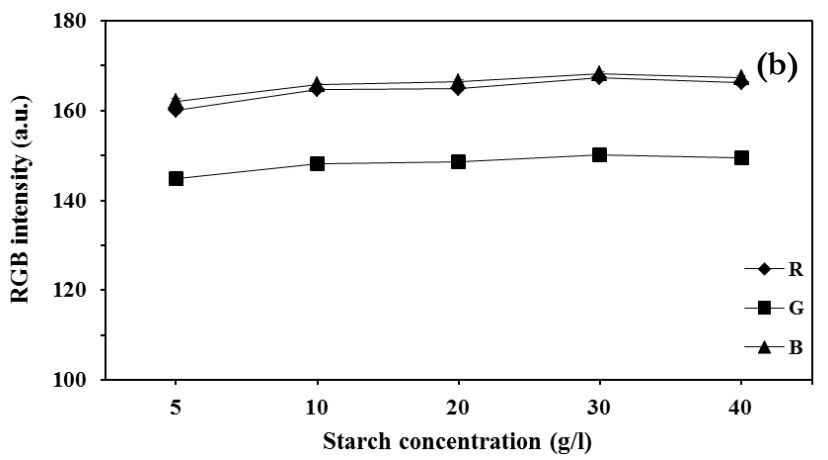

Fig. 6. Effect of (a) agar and (b) starch concentration on RGB intensities of the reaction products. 


\subsection{Effect of Incubated Temperature and Time}

After $100 \mu \mathrm{L}$ mixture of the buffer-containing DPD reagent and polymer solution were dropped on the testkit lid, the polymerization was operated at high temperature. The effect of incubated temperature and time was studied in the range of $50-110^{\circ} \mathrm{C}$ and $20--90$ min, respectively. As exhibited in Fig. 7(a), the best performance of sensor kit was obtained by the highest substracted RGB intensity at $70{ }^{\circ} \mathrm{C}$. The film polymerization at higher temperature was resulted in the regression of substracted intensity. This implied that the excess energy delivered to the polymer could deteriorate the film structure and homogeneity. Some parts of film were turned brown as noticed by naked eye. Since RGB

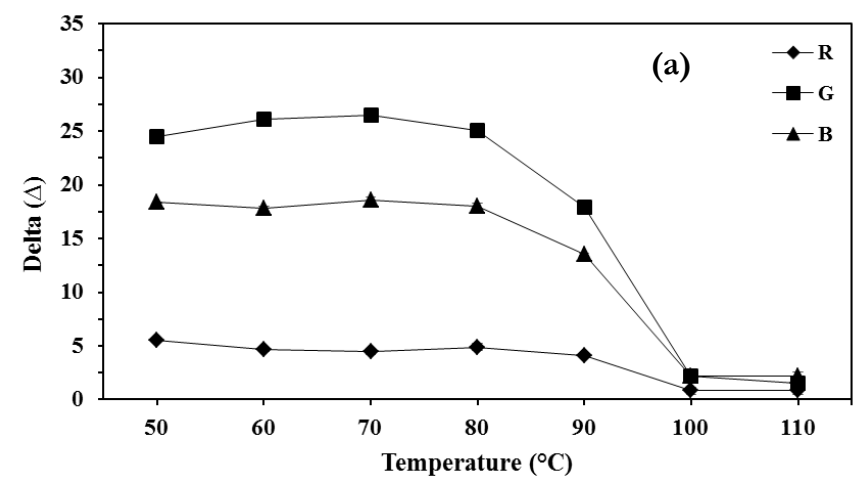

intensity from $60{ }^{\circ} \mathrm{C}$ and $70{ }^{\circ} \mathrm{C}$ incubated films was different less than $4 \%$, the the polymerization at $60{ }^{\circ} \mathrm{C}$ was selected as the optimum incubated temperature to save the energy for the film production.

For the effect of incubated time as presented in Fig. 7(b), there was insignificantly difference in the substracted RGB intensity over the studied range, even at short incubated time where the film did not formulated. This indicated the trapping of chromogenic species by polymer did not obstruct to its diffusion to the water phase. That's why the substracted RGB intensity from DPD in reagent condition was not different with those of film condition. However, the incubated time was recommended at $60 \mathrm{~min}$ (for $60^{\circ} \mathrm{C}$ ), because of the film thrououghly formulated without any liquid textures.

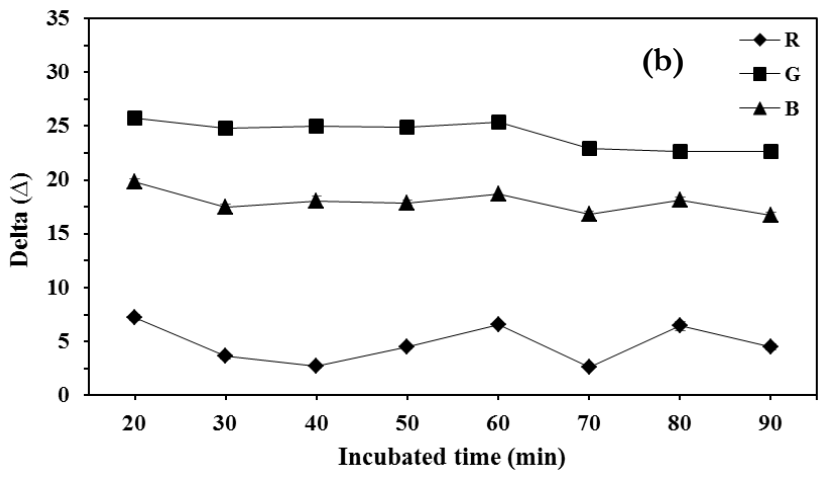

Fig. 7. Effect of the (a) incubated temperature and (b) time on RGB intensities of reaction products

\subsection{Effect of Reaction Time on the Chlorine Measurement}

The effect of time on the reaction between chlorine and DPD from the thin film under the synthetic condition optimized as above was studied in the range of $0-30 \mathrm{~min}$. The experimental results revealed that the color product was completely generated within $1 \mathrm{~min}$, as shown in terms of the maximum substracted RGB intensity in Fig. 8. However, the subtracted intensity was trended to decrease when the reaction time was longer than $4 \mathrm{~min}$. There were 2 possible reasons. First, the increasing in dissolution of color reagent from the blank film could be detected and it was therefore resulted in the substracted RGB value. Second, the color product could be destabilized at longer reaction time. To prevent the discolor of subtracted RGB, the optimum time for detection should be applied at $1 \mathrm{~min}$.

\subsection{Quantification of Chlorine by Using the Biopolymer Test Kit with DIC}

After the optimum condition of film fabrication was determined, the test kit was ready-to-use for qualitative analysis. However, the rapid quantitative information could be also achieved by the developed film in conjuction with DIC. The pink complexes obtained from testing the film with the chlorine standard solution at different concentration were photographed and analyzed for RGB intensities. The relationship between chlorine concentrations and RGB values was plotted as the calibration curve (as shown in Fig. 9(a)) and the linear equation was then determined as a key element for quantitative analysis. In constrast with the green $\left(\mathrm{I}_{\mathrm{G}}\right)$ and blue intensities $\left(\mathrm{I}_{\mathrm{B}}\right)$, the red intensity $\left(\mathrm{I}_{\mathrm{R}}\right)$ was hardly changed with the chlorine concentration. It was lower than $I_{G}$ and $I_{B}$ at low concentration. However, $I_{R}$ became the highest one, when other two intensities was decreased, especially at higher concentration than 7 $\mathrm{mg} / \mathrm{L}$. This was due to the darkening of pink complex formed, as noticed by naked eye (Fig. 10), at initial concentration level of $7 \mathrm{mg} / \mathrm{L}$.

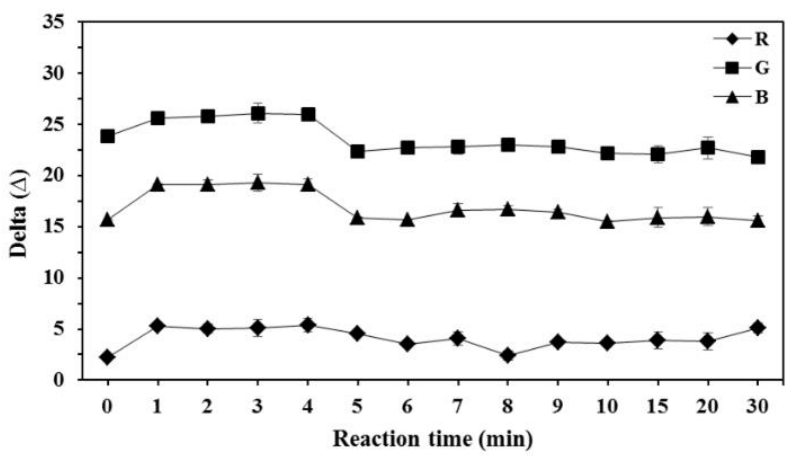

Fig. 8. Reaction time of chlorine and DPD from the sensor film. 

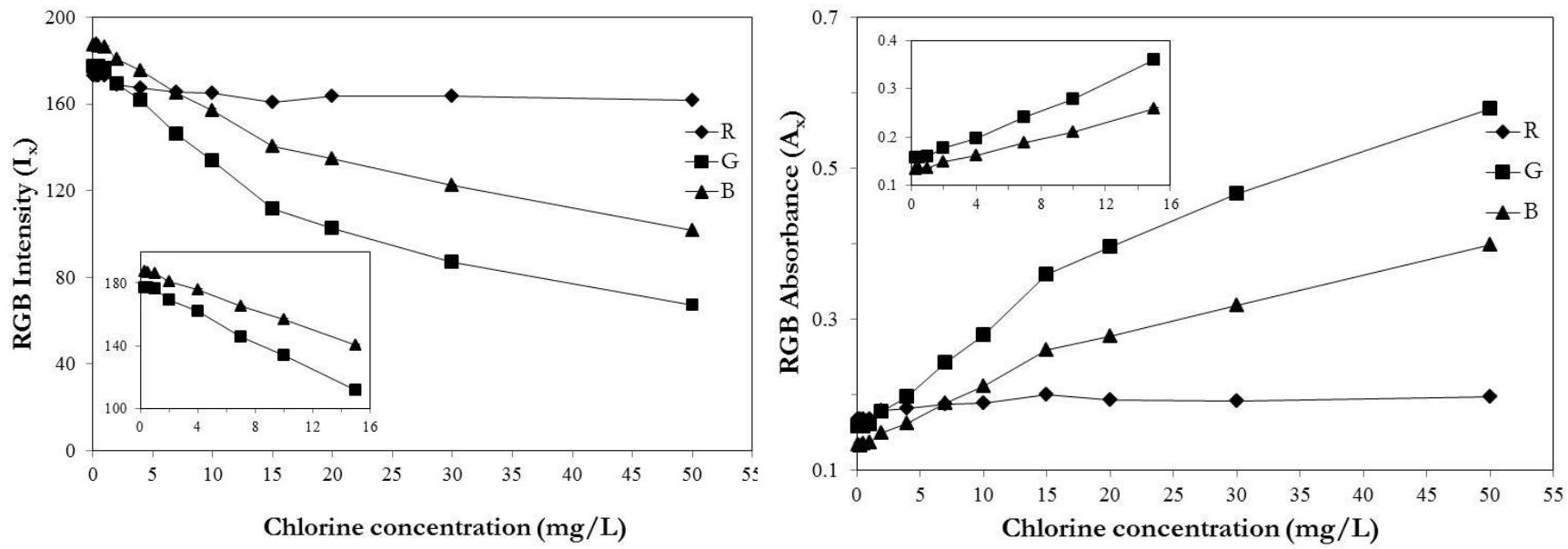

Fig. 9. Relationships between free chlorine concentrations and (a) RGB intensities and (b) calculated RGB absorbances.

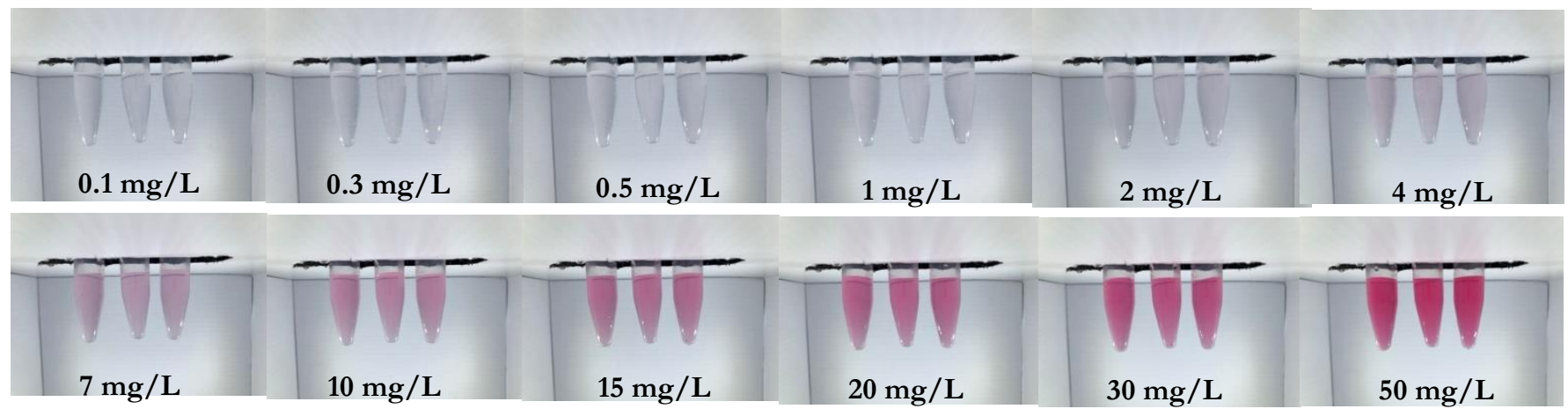

Fig. 10. Colorimetric products of chlorine from testing with the biopolymer test kit.

In the standard method based on spectrophotometry, the absorbance of the colorimetric product was a key parameter playing an important role in its measurement. For DIC technique, the absorbance could be estimated from each color band intensity by using Eq. (1) [21, 3940]:

$$
A_{X}=-\log \frac{\left(I_{X}-I_{X, b}\right)}{\left(I_{X, w}-I_{X, b}\right)}=-\log \frac{\left(I_{X}\right)_{c}}{\left(I_{X, w}\right)_{c}}
$$

where for each $\mathrm{X}$ color $(\mathrm{R}, \mathrm{G}, \mathrm{B}), \mathrm{A}_{\mathrm{X}}$ was the absorbance of $\mathrm{X}, \mathrm{I}_{\mathrm{X}}$ was the intensity of $\mathrm{X}, \mathrm{I}_{\mathrm{X}, \mathrm{b}}$ was the intensity of black color or $0, \mathrm{I}_{\mathrm{X}}$, w was the intensity of white color or 255, and $\mathrm{C}$ was the concentration of $\mathrm{X}$.

Accordings to Fig. 9(b), an inverse relationship was obtained by calculated absorbance profile and the green channel (500-580 nm) dominated in absorbance over the blue (430-470 nm) and red channels (660 - $760 \mathrm{~nm})$. These results indicated that the pink complexes could remarkably absorb the visible light in the green and blue ranges, while they reflected red light. This was in good agreement with spectrophotometric results that the pink complex provided the maximum absorbance at $515 \mathrm{~nm}$ [37], standing in the wavelength of green region.

Both intensities and calculated absorbances exhibited a linear relationship with the chlorine concentration which offered a convenient means of quantifying chlorine. As summarized in Table 2, the linear portions for $I_{G}, I_{B}, A_{G}$ and $A_{B}$ were in the same range of $0.3-15$ $\mathrm{mg} / \mathrm{L}$ chlorine with good linearity $\left(\mathrm{R}^{2}>0.99\right)$. However, the sensitivity provided by the intensity value seems better than those by absorbance. The $\mathrm{I}_{\mathrm{G}}$ possessed the highest sensitivity of 4.5449 a.u. $\mathrm{L} / \mathrm{mg}$, while the lowest one of 0.0085 a.u. $\mathrm{L} / \mathrm{mg}$ was fed by $\mathrm{A}_{\mathrm{B}}$. In addition to the greatest linearity $\left(R^{2}=0.9984\right)$, the $I_{G}$ was obtained directly from the analysis of a digital image, unlike the molecular absorption calculated from the intensity. Thus, the $I_{G}$ was recommended for quantification of chlorine. 
Table 2. Calibration equation and linear range for chlorine detection by using the colorimetric film and DIC.

\begin{tabular}{cccc}
\hline Parameter & $\begin{array}{c}\text { Calibration equation } \\
\text { (unit of } \mathbf{y}=\mathbf{a . u} \text {. and } \\
\mathbf{x}=\mathbf{m g} / \mathbf{L})\end{array}$ & $\begin{array}{c}\text { Linear range } \\
(\mathbf{m g} / \mathbf{L})\end{array}$ & Linearity $\left(\mathbf{R}^{2}\right)$ \\
\hline $\mathrm{I}_{\mathrm{G}}$ & $\mathrm{y}=-4.5449 \mathrm{x}+179.24$ & $0.3-15$ & 0.9984 \\
$\mathrm{I}_{\mathrm{B}}$ & $\mathrm{y}=-3.2061 \mathrm{x}+188.29$ & $0.3-15$ & 0.9982 \\
$\mathrm{~A}_{\mathrm{G}}$ & $\mathrm{y}=0.0136 \mathrm{x}+0.1488$ & $0.3-15$ & 0.9960 \\
$\mathrm{~A}_{\mathrm{B}}$ & $\mathrm{y}=0.0085 \mathrm{x}+0.130$ & $0.3-15$ & 0.9975 \\
\hline
\end{tabular}

\subsection{Analysis of Real Water Sample}

Four water samples were randomly collected from each water sources possibly contaminated by chlorine, i.e. the swimming pool, salt water pool, tap water and sea water at Patong beach, Phuket. The average concentrations were analyzed by using the biopolymer film in conjunction with DIC, and spectrophotometry for comparison. The results were shown in Table 3.

Except sea water, the free chlorine was found in all samples. In the traditional swimming pool, the chlorine concentration quantified by the proposed method was $1.73 \mathrm{mg} / \mathrm{L}$, comparable with $1.87 \mathrm{mg} / \mathrm{L}$ from the standard spectrophotometric technique. The level of chlorine in the conventional pool was higher than the modern salt pool, where they were found at 0.56 and 0.62 for the test kit and spectrophotometric detection, respectively. This was because the free chlorine was added directly to the water in the traditional pool, while hypochlorous acid (free chlorine) was turned from the sodium chloride via electrolysis process in the salt pool. The chlorine concentrations found in both pool samples did not exceed the level of 3-5 mg/L, suggested by World Health Organization (WHO) for safe swimming pool from the harmful disinfection by-product [41]. For the tap water sample, the chlorine concentration was detected at $1.34 \mathrm{mg} / \mathrm{L}$ by the developed test kit, which was in a good agreement with $1.39 \mathrm{mg} / \mathrm{L}$ chlorine from spectrophotometric method (only $3.60 \%$ relative error). Noted that the amount of chlorine in the tap water sample was also under the concentration degree of 1.0 $1.5 \mathrm{mg} / \mathrm{L}$ controlled by Thai Provincial Waterworks Authority. Statistically, all results from the proposed method were not significantly different with the standard spectrophotometric technique at 95\% confidence level (calculated $t$-value $=0.94$, and critical $\mathrm{t}$-value $=2.45$ ). This indicated the excellent performance of the biopolymer hybrid film combined with DIC for the analysis of chlorine in water samples.

Table 3. Concentration of free chlorine in various water sample.

\begin{tabular}{cccc}
\hline \multirow{2}{*}{ Sample } & \multicolumn{2}{c}{ Chlorine concentration } & \%Relative Error \\
\cline { 2 - 3 } & $\begin{array}{c}\text { Developed test kit } \\
(\mathbf{m g} / \mathbf{L})\end{array}$ & $\begin{array}{c}\text { Spectrophotometry } \\
(\mathbf{m g} / \mathbf{L})\end{array}$ & \%Rec \\
\hline Swimming pool & 1.73 & 1.87 & 7.49 \\
Salt water pool & 0.56 & 0.62 & 9.68 \\
Tap water & 1.34 & 1.39 & 3.60 \\
Sea water & n.d.* & n.d. & - \\
n.d. $=$ not detected & & &
\end{tabular}

\section{Conclusion}

A novel film of hybrid biopolymer was successfully developed from the crosslinkage of two natural products, i.e. the tapioca starch and agar. It was employed to entrap $\mathrm{N}, \mathrm{N}$-diethyl-p-phenylenediamine (DPD) colorimetric indicator for free chlorine analysis. The analytical film was in-situ coated on the lid of plastic micro-PCR tube so that $1 \mathrm{~mL}$ water sample could directly added into the tube, acting as the portable color reactor. The hybrid film would be well prepared from the mixture of 3 solutions, i.e. $0.5 \mathrm{~mL}$ phosphate buffer containing $16 \mathrm{~g} / \mathrm{L}$ EDTA, 1 $\mathrm{mL}$ of $0.2 \mathrm{~g} / \mathrm{mL}$ DPD reagent and $3.5 \mathrm{~mL}$ of $2: 1(\mathrm{v} / \mathrm{v})$ $2.5 \mathrm{~g} / \mathrm{L}$ agar : $5 \mathrm{~g} / \mathrm{L}$ starch soulution. One hundred microliter of those mixture dropped on the plastic lid was polymerized at $60^{\circ} \mathrm{C}$ for $60 \mathrm{~min}$ to obtain the best performance film. The testkit showed very fast response of $1 \mathrm{~min}$ for the development of pink product color, after $1 \mathrm{~mL}$ of chlorine sample added into the tube. When the developed film sensor was used in combination with digital image colorimetry (DIC), it provided an ideal novel platform for the rapid quantitative analysis of free chlorine. The good linear response with wide range of $0.3-15 \mathrm{mg} / \mathrm{L}$ at greatest linearity $\left(\mathrm{R}^{2}=0.9984\right)$ was achieved. This indicated the possibility of application for the portable, rapid, cost-effective and environmentally friendly testkit. 


\section{Acknowledgements}

Authors would like to thank for the funding and facility supporting by Faculty of Technology and Environment, Prince of Songkla University, Phuket Campus. It was also appreciate to the Office of Higher Education Commission (OHEC), the S\&T Postgraduate Education and Research Development Office (PERDO) and Center of Excellence on Hazardous Substance Management (HSM), Chulalongkorn University for their invaluable supports in terms of financial seeding.

\section{References}

[1] Hydro Instruments, "Basic chemistry of chlorination," 2018.

[2] Occidental Chemical Corporation, "Sodium chlorite chlorine dioxide treatment of industrial \& municipal pollutants," 2018.

[3] T. L. Engelhardt and V. B. Malkov, Chlorination, Chloramination and Chlorine Measurement. Hach Company, 2013.

[4] K. H. Baker, J. P. Hegarty, B. Redmond, N. A. Reed, and D. S. Herson, "Effect of oxidizing disinfectants (chlorine, monochloramine, and ozone) on Helicobacter prylori," Appl. Environ. Microbiol, vol. 68, no. 2, pp. 981-984, 2002.

[5] K. L. Simpson and K. P. Hayes, "Drinking water disinfection by-products: An Australian perspective," Water Res., vol. 32, no. 5, pp. 1522-1528, 1998.

[6] E. K. Wujcik, S. E. Duirk, G. G. Chase, and C. N. Monty, "A visible colorimetric sensor based on nanoporous polypropylene fiber membranes for the determination of trihalomethanes in treated drinking water," Sensors Actuators B. Chem., vol. 223, pp. 1-8, 2016.

[7] F. Bove, Y. Shim, and P. Zeitz, "Drinking water contaminants and adverse pregnancy outcomes: A review," Environ. Health Perspect., vol. 110, no. August 2001, pp. 61-74, 2002.

[8] World Health Organization, Guidelines for Drinking water Quality, 4th ed. Geneva, 2011.

[9] American National Standard for Water Quality in Public Pools and Spas, American National Stands Institute (ANSI), Alexandria, 2009.

[10] U.S. Environmental Protection Agency, Drinking $W$ ater Standards and Health Advisories Office of Water. 2000.

[11] Notification of the Industrial Estate Authority of Thailand, General Rules for Wastewater Discharge into the Central Wastewater Treatment System in Industrial Estates. 1998, no. 78, pp. 113-117.

[12] J. Sullivan and M. Douek, "Determination of inorganic chlorine species in kraft mill bleach effluents by ion chromatography," J. Chromatogr. A, vol. 804, no. 1-2, pp. 113-121, 1998.

[13] M. Szili, I. Kasik, V. Matejec, G. Nagy, and B.
Kovacs, "Poly(luminol) based sensor array for determination of dissolved chlorine in water," Sensors Actuators, B Chem., vol. 192, pp. 92-98, 2014.

[14] Y. Dong, G. Li, N. Zhou, R. Wang, Y. Chi, and G. Chen, "Graphene quantum dot as a green and facile sensor for free chlorine in drinking water," Anal. Chem., vol. 84, no. 19, pp. 8378-8382, 2012.

[15] F. J. Del Campo, O. Ordeig, and F. J. Muñoz, "Improved free chlorine amperometric sensor chip for drinking water applications," Anal. Chim. Acta, vol. 554, no. 1-2, pp. 98-104, 2005.

[16] A. R. Zarei and M. R. Sovizi, "Application of cloud point extraction technique to preconcentration and spectrophotometric determination of free chlorine in water samples," J. Anal. Chem., vol. 66, no. 3, pp. 269-274, 2011.

[17] L. Moberg and B. Karlberg, "An improved N,N'diethyl-p-phenylenediamine (DPD) method for the determination of free chlorine based on multiple wavelength detection," Anal. Chim. Acta, vol. 407, no. 1-2, pp. 127-133, 2000.

[18] Y. Xiong et al., "A LED-based fiber-optic sensor integrated with lab-on-valve manifold for colorimetric determination of free chlorine in water," Talanta, vol. 167, no. February, pp. 103-110, 2017.

[19] Y. S. Uzuki, M. E. Ndo, J. J. In, K. I. Wase, and M. I. Watsuki, "Tristimulus colorimetry using a digital still camera and its application to determination of iron and residual chlorine in water samples," Anal. Sci., vol. 22, Mar. 2006.

[20] M. L. Firdaus, W. Alwi, F. Trinoveldi, I. Rahayu, L. Rahmidar, and K. Warsito, "Determination of chromium and iron using digital image-based colorimetry," in Procedia Environmental Sciences, 2014, vol. 20, pp. 298-304.

[21] A. Choodum and N. Nic, "Digital image-based colourimetric tests for amphetamine and methylamphetamine," Drug Test. Anal., no. January, pp. 277-282, 2011.

[22] A. Lopez-Molinero, D. Liñan, D. Sipiera, and R. Falcon, "Chemometric interpretation of digital image colorimetry. Application for titanium determination in plastics," Microchem. J., vol. 96, no. 2, pp. 380-385, 2010.

[23] L. M. Goddijn and M. White, "Using a digital camera for water quality measurements in Galway Bay," Estuar. Coast. Shelf Sci., vol. 66, pp. 429-436, 2006.

[24] A. Choodum, K. Parabun, N. Klawach, and N. Nic, "Real time quantitative colourimetric test for methamphetamine detection using digital and mobile phone technology," Forensic Sci. Int., vol. 235, pp. 8-13, 2014.

[25] A. Choodum, P. Kanatharana, and W. Wongniramaikul, "Using the iPhone as a device for a rapid quantitative analysis of trinitrotoluene in soil," Talanta, vol. 115, pp. 143-149, 2013.

[26] T. Garrido, A. Etxabide, P. Guerrero, and K. De 
Caba, "Characterization of agar/soy protein biocomposite films: Effect of agar on the extruded pellets and compression moulded films," Carbobydr. Polym., vol. 151, pp. 408-416, 2016.

[27] M. Dimopoulou, C. Ritzoulis, and E. S. Papastergiadis, "Composite materials based on okra hydrocolloids and hydroxyapatite," Food Hydrocoll., vol. 42, pp. 348-354, 2014.

[28] L. Prietto et al., " $\mathrm{pH}$-sensitive fi lms containing anthocyanins extracted from black bean seed coat and red cabbage," LWT - Food Sci. Technol., vol. 80, pp. 492-500, 2017.

[29] O. Lopez, M. A. Garcia, M. A. Villar, A. Gentili, M. S. Rodriguez, and L. Albertengo, "Thermocompression of biodegradable thermoplastic corn starch films containing chitin and chitosan," LWT Food Sci. Technol., vol. 57, no. 1, pp. 106-115, 2014.

[30] T. Bourtoom and M. S. Chinnan, "Preparation and properties of rice starch e chitosan blend biodegradable film," LWT - Food Sci. Technol., vol. 41, pp. 1633-1641, 2008.

[31] J. F. Mendes et al., "Biodegradable polymer blends based on corn starch and thermoplastic chitosan processed by extrusion," Carbohydr. Polym. J, vol. 137, pp. 452-458, 2016.

[32] C. Medina-Jaramillo, O. Ochoa-yepes, C. Bernal, and L. Famá, "Active and smart biodegradable packaging based on starch and natural extracts," Carbohydr. Polym., vol. 176, no. May, pp. 187-194, 2017.

[33] R. Jumaidin, S. M. Sapuan, M. Jawaid, M. R. Ishak, and J. Sahari, "Characteristics of thermoplastic sugar palm Starch/Agar blend: Thermal, tensile, and physical properties," Int. J. Biol. Macromol., vol. 89, pp. 575-581, 2016.

[34] I. Choi, J. Young, M. Lacroix, and J. Han,
"Intelligent $\mathrm{pH}$ indicator film composed of agar / potato starch and anthocyanin extracts from purple sweet potato," Food Chem., vol. 218, pp. 122-128, 2017.

[35] Y. Wu, F. Geng, P. R. Chang, J. Yu, and X. Ma, "Effect of agar on the microstructure and performance of potato starch film," Carbohydr. Polym., vol. 76, no. 2, pp. 299-304, 2009.

[36] D. Phan The, F. Debeaufort, A. Voilley, and D. Luu, "Biopolymer interactions affect the functional properties of edible films based on agar, cassava starch and arabinoxylan blends," J. Food Eng., vol. 90, no. 4, pp. 548-558, 2009.

[37] Standard Methods for Examination of $W$ ater and $W$ astewater, 23th ed, APHA, AWWA, WOCF, 2017.

[38] N. M. R. and R. A. S. William J. Cooper, "Determining free available chlorine by DPDcolorimetric, DPD-Steadifac (colorimetric), and FACTS procedures," Am. Water Work. Assoc., vol. 74, no. 7, pp. 362-368, 1982.

[39] W. Wongniramaikul, W. Limsakul, and A. Choodum, "A biodegradable colorimetric film for rapid low-cost field determination of formaldehyde contamination by digital image colorimetry," Food Chem., vol. 208, pp. 40-47, 2018.

[40] A. Choodum, V. Jirapattanasophon, C. Boonkanon, T. Taweekarn, and W. Wongniramaikul, "Difluoroboroncurcumin doped starch film and digital image colorimetry for semi-quantitative analysis of arsenic,' Anal. Sci., vol.36, no. 5, pp. 577-582, 2020.

[41] M. R. Tomei, F. Arduini, D. Neagu, and D. Moscone, "Carbon black-based disposable sensor for an on-site detection of free chlorine in swimming pool water," Talanta, vol. 189, pp. 262$267,2018$.

Worawit Wongniramaikul, photograph and biography not available at the time of publication.

Hataikran Sangtong, photograph and biography not available at the time of publication.

Aree Choodum, photograph and biography not available at the time of publication. 